basic processes. Such modelling results are described comprehensively here. Researchers at the new Center for the Analysis and Prediction of Storms in Oklahoma plan to construct a forecast model capable of predicting the development and evolution of thunderstorms dayby-day. Until that enterprise is successful the most advanced operational mesoscale forecast model, at the UK Meteorological Office, has a horizontal resolution of

Within the field defined by the authors few stones are left unturned. The style of the book is one in which the body of knowledge on a given topic is summarized comprehensively, which makes the volume a storehouse of invaluable information. It does not, on the whole, present the authors' viewpoint or perspective. This is not to say that the authors have not contributed significantly to research in mesoscale meteorology. They have, and they make reference to their work, but about 15 kilometres.

their vision of the subject is not clearly evident here.

I am sure that this book will be read by all mesoscale meteorologists, and particularly by graduate students and people about to enter the field. Of course, one can quibble about what is included and what glossed over. The sections on cumulonimbus dynamics and on mesoscale convective systems are good, whereas that on frontal rainband dynamics is cursory and misleading. One might question the need for so much on airflow over mountains, cloud parameterization and radiative transfer in a book on cloud dynamics.

In conclusion, the authors provide a scholarly account of a large, actively developing topic. The result is immensely useful.

Alan J. Thorpe is in the Department of Meteorology, University of Reading, Whiteknights, Reading RG6 $2 A U$, UK.

\section{Cashing chips}

\author{
Richard L. Gregory
}

The Industrialization of Intelligence: Mind and Machine in the Modern Age. By Noah Kennedy. Unwin Hyman: 1989. Pp. 213. £14.95, $\$ 24.95$.

Starting with the great library in Alexandria and its tragic loss, and ending with an analysis of the role of computers in present-day society with speculations for the future, this book is an essay on the significance of mechanized intelligence from papyrus scrolls to silicon chips. In the middle we meet artificial intelligence: whether brains are intelligent computers, and whether computers can be intelligent brains. This is a fascinating question which may be thought of as purely empirical - is it actually possible to make fully intelligent computers? - or as philosophical. John Searle argues on philosophical grounds that computers can handle only syntax, without appreciating meaning. He argues this by analogy with a closed room in which Chinese symbols are moved around correctly though without understanding. Kennedy's conclusion is that what Searle's chinese room argument "has really done is to muddy the crystalline waters of the strong AI approach". One might indeed agree, but even if it has not provided direct light the debate at least has inspired some productive heat. The interest is to follow the debate; but this requires a depth of description and analysis of sometimes technical issues. These are generally lacking here, which makes The Industrialization of Intelligence, despite its dramatic and important theme, curiously featureless and flat.

In this book one does not find definitions of intelligence, or of creativity, and comparisons between human and machine 'mental' performance are sadly lacking. Some pictures would have helped. Why have a long detailed description of the layout of a Babbage computer have conveyed it clearly at a glance?

The assemblage of scholarship on some significant issues may be useful, especially perhaps for planning future industrialization of intelligence. One is reminded that at the start of the computer revolution the British government estimated that but two computers, at most, would be required.

Richard L. Gregory is in the Department of Psychology, University of Bristol, Bristol BS8 $1 \mathrm{HH}, \mathrm{UK}$.

\section{Spring Books}

NEXT week is Nature's Spring Books issue. Books to be reviewed include the autobiography of Hans Eysenck and the second volume of the collected papers of Albert Einstein. Daniel S. Greenberg discusses the relationship between scientists and the government agencies that support them. David Owen, leader of Britain's Social Democratic Party, analyses a prediction of the problems that will face the United States and Japan, in particular, by the end of the century. There are stories of explorers: Admiral Peary's disputed claim to have reached the Pole is reassessed in the light of new 'scientific' evidence, and the story of the exploration of the Amazon is told. There are accounts of the history of science: medical research in Britain and the development of the field of biological oceanography. The monumental work The Ants, by $\mathrm{B}$. Hölldobler and E. O. Wilson, is reviewed, and on a lighter note, Walter Gratzer turns his attention to that indispensable accessory, the pencil. when a line drawing or photograph would

\section{Out of sight}

\section{Stuart Sutherland}

Neuropsychology of Visual Perception. Edited by Jason W. Brown. Erlbaum Associates: 1989. Pp.267. £29.95, \$49.95.

THE following story about the late Professor Oliver Zangwill illustrates the complexity of the effects of brain damage. Zangwill once investigated a patient with severe visual agnosia, that is the inability to recognize objects by eye. At the beginning of the first session, Zangwill showed his own magnificent blue fountain pen to the patient and asked him to try to remember it. When Zangwill presented it again at the end of the session, the patient completely failed to recognize it. This procedure, with the same pen and with the same result, was repeated for ten sessions. At the end of the final session, when the patient yet again failed to recognize the pen, Zangwill, at his wits' end, asked, "Do you know who $I$ am?". "Of course", said the patient unhesitatingly, "you're the man with all those fountain pens".

Until fairly recently, work on braindamaged patients was directed almost wholly at discovering in which part of the brain a particular function is carried out. Nowadays, neuropsychologists believe that investigating the differential loss of different functions may shed light on how the normal brain works. For simple functions, this approach has sometimes produced results that are readily interpretable. For example, patients may lose colour vision while retaining the ability to see motion, or vice versa. In fact little was made of this finding until it was discovered by microelectrode recording that colour vision and motion perception are subserved by different areas of the visual cortex. Unfortunately, neuropsychologists have not helped to uncover the brain mechanisms that underlie either function: for that we have to turn to psychological work on normal people and to recent neurophysiological findings with microelectrodes.

To take more complex abilities, Neuropsychology of Visual Perception contains evidence from brain-damaged patients that object recognition and route finding are also dissociable. But when one reads the comprehensive and informative chapter by M. J. Riddoch and G. W. Humphreys on the latter topic, it becomes obvious that this ability can itself break down in many different ways, even though most of the lesions that give rise to it are in approximately the same part of the parietal lobe. Some patients can continue to find their way around a familiar environment, but cannot read a map or draw a plan; for others these defects are reversed. In some cases, depth vision is 